\title{
EVIDENCIAÇÃO AMBIENTAL: UM ESTUDO COMPARATIVO DAS INFORMAÇÕES AMBIENTAIS DIVULGADAS PELAS EMPRESAS DO SETOR DE PETRÓLEO, GÁS E BIOCOMBUSTÍVEIS NO PERÍODO DE 2015 A 2017
}

\section{ARTIGO ORIGINAL}

LEITE, Michael Douglas Sousa ${ }^{1}$

BELCHIOR, Sandra Maijane Soares de ${ }^{2}$

BELCHIOR, Verônica Cristian Soares de ${ }^{3}$

LACERDA, Wendell de Almeida ${ }^{4}$

PIRES, Maria José Soares de Belchior ${ }^{5}$

SILVA, Cleuton de Sousa ${ }^{6}$

\footnotetext{
${ }^{1}$ Mestrando em Sistemas Agroindústrias - UFCG, Pós-Graduado em Docência do Ensino Superior, Graduado em Administração - UFCG.

2 Mestranda em Sistemas Agroindústrias - UFCG, Pós-Graduada em Gestão Econômica e estratégias de Negócios-FIP, Graduada em Ciências Econômicas.

3 Mestranda em Sistemas Agroindústrias - UFCG, Pós-Graduada em Ciências Políticas da Educação, Graduada em Ciências Econômicas.

${ }^{4}$ Mestre em Sistemas Agroindústrias - UFCG, MBA Auditoria Contábil - FIP, Especialista em Psicopedagogia - FIP, Graduado em Administração.

${ }^{5}$ Mestranda em Sistemas Agroindústrias - UFCG, Graduada em Serviço Social.

${ }^{6}$ Mestrando em Sistemas Agroindústrias - UFCG, Pós-Graduado em Gestão de Políticas de Patrimônio Cultural (UNINASSAU), Graduado em Arquitetura e Urbanismo (UFPB).
} 
SILVA, Oziel Oliveira da ${ }^{7}$

LEITE, Michael Douglas Sousa. Et al. Evidenciação ambiental: Um estudo comparativo das informações ambientais divulgadas pelas empresas do setor de Petróleo, Gás e Biocombustíveis no período de 2015 a 2017. Revista Científica Multidisciplinar Núcleo do Conhecimento. Ano 05, Ed. 11, Vol. 13, pp. 126-148. Novembro de 2020. ISSN: 2448-0959, Link de acesso:https://www.nucleodoconhecimento.com.br/sem-categoria/evidenciacaoambiental

\section{RESUMO}

As empresas do ramo petroquímico são provedoras de bens e serviços e grandes consumidoras de recursos naturais e tradicionais fontes poluidoras, causando muitos problemas ambientais no planeta. A sociedade tem cobrado das empresas, uma nova postura quanto ao alinhamento do desenvolvimento econômico à responsabilidade ambiental. Assim, as políticas ambientais, no âmbito legal, moral e ético que são implantadas pelas empresas, devem ser geridas e seus resultados evidenciados aos stakeholders. Nesse sentido, a presente pesquisa buscou verificar as informações ambientais, publicadas pelas empresas do setor Petróleo, Gás e Biocombustíveis listadas na Bovespa no período de 2015 a 2017. Para tanto, a presente pesquisa tratou-se de um estudo bibliográfico, descritivo, documental e quantiqualitativo. A coleta de dados foi realizada através dos sites da BOVESPA e sites oficiais das empresas selecionadas. Os resultados mostraram que as empresas com o maior número de informações ambientais divulgadas em seus instrumentos de evidenciação foram a Petrobras e Ultrapar apresentando um número maior de informações ambientais que as outras empresas pesquisadas. Assim as outras empresas, as informações ambientais divulgadas são insuficientes para compreender como essas

\footnotetext{
7 Mestrando em Sistemas Agroindústrias - UFCG, Pós-Graduado em Ensino de Química, Graduado em Licenciatura em Química.
} 
empresas identificam, mensuram e registram os fenômenos ambientais, bem como as políticas de sustentabilidade ambiental adotadas por elas.

Palavras-Chave: Evidenciação, Gestão Ambiental, Empresas Petroquímicas.

\section{INTRODUÇÃO}

Ao longo do último século, os níveis altos de degradação gerados pela ação do homem ao meio ambiente vêm acendendo uma maior conscientização acerca dos problemas ambientais que afetam o planeta Terra.

O aumento de uma consciência ecológica para Lima et al. (2012) foi o incentivo para que a população passasse a exigir informações acerca dos padrões que deveriam ser adotados pelas organizações para conter os impactos gerados por suas atividades ao meio ambiente. Colaborando Rover et al. (2008) relatam que devido à necessidade de evidenciar informações sobre a interação da organização com o meio ambiente, a Contabilidade, passou a ser um instrumento gerador de informações, sendo utilizada como veículo de comunicação entre organização/sociedade.

Carneiro et al. (2008) revelam a preocupação de países e da sociedade com a degradação do meio ambiente e com o consumo excessivo dos recursos naturais. As organizações se responsabilizam por boa parcela de agressão ao meio ambiente, por estas serem as principais consumidoras dos recursos naturais e ainda fontes permanentes de poluição. Desse modo, as sociedades com maior preocupação com a questão ambiental não têm medido esforços para exigir uma legislação rígida por parte de governos, buscando disciplinar a atividade econômica, dentre outras ações.

Nessas sociedades, para os autores supramencionados os consumidores têm demonstrado uma nova consciência ecológica nos seus hábitos de consumo. Muitos consumidores exigem certificação ambiental como os selos concedidos a organizações que adotam políticas de responsabilidade ambiental, além disso, as organizações têm buscado implementar sistemas de gestão de recursos ambientais, cumprindo a legislação referente ao meio ambiente e adotando relações transparentes com seus grupos de interesse (stakeholders). 
Como o objetivo da contabilidade é fornecer informação estruturada de natureza financeira, econômica, e, subsidiariamente, física de produtividade e social, aos usuários à entidade objeto da Contabilidade (IUDÍCIBUS, 2015; LIMA et al., 2012). Portanto, o ramo da Contabilidade Ambiental é um ramo da Ciência Contábil relativamente novo o que trouxe o interesse pelo tema (ECKERT et al., 2014).

Desse modo, a Contabilidade Ambiental pode ser vista como um instrumento que, por meio da identificação e do registro dos eventos ambientais, fornece ao usuário informações para auxiliar a tomarem decisões buscando à mitigação e controle dos impactos causados pelas atividades empresariais ao meio ambiente.

Neste contexto, a Contabilidade, pode contribuir divulgando as informações das empresas tanto de caráter econômico-financeiro como também ambiental, assim, considerando a importância da divulgação das informações de natureza ambiental das organizações, esta pesquisa propõe-se verificar as informações ambientais, publicadas pelas empresas do setor Petróleo, Gás e Biocombustíveis listadas na Bovespa no período de 2015 a 2017.

A relação da organização/sociedade precisa ser de transparência, sendo leal e fiel a realidade dos fatos e exibindo também os problemas ambientais gerados pela entidade e as possíveis soluções implementadas, mesmo que a organização corra sério risco de sofrer pressões do Estado e da sociedade. Destarte, a organização sinaliza que respeita a sociedade em que se insere e zela pela sua relação.

Tal questão, compreende a relevância diante de uma posição socialmente responsáveis desenvolvidas pelas organizações quanto à preservação do meio ambiente e relações com os usuários (internos e externos). Krespi et al. (2012, p. 148) relatam que "a importância de seguir uma postura socialmente responsável, aumenta à medida que se torna claro que uma sociedade mais fragilizada representa o risco para os próprios negócios das organizações". Nesse sentido, "ser socialmente responsável passou a ser mais do que apenas cumprir as obrigações sociais e tornouse ponto estratégico, além de ser fator de diferencial competitivo". 
Ao produzirem informações de grande relevância das suas atividade e atitudes socialmente responsáveis, é preciso que as organizações divulguem as respectivas informações ao mercado, utilizando-se da contabilidade ambiental como ferramenta.

Optou-se pelas empresas do setor de Petróleo, Gás e Biocombustíveis listadas no site da Bovespa, por ser um setor de grande impacto ambiental, e com isso defrontam-se com a precisão de implementar políticas ambientais que reduzem ou eliminam os efeitos danosos sobre o meio ambiente. No entanto, a questão não se epiloga à prática de políticas de gestão visando à sustentabilidade ambiental. É preciso que a organização divulgue para a sociedade as suas efetivações na área ambiental, além das informações acerca das políticas que a mesma adota, o quanto a sua atividade impacta diretamente ou indiretamente o meio ambiente, quais as metas e objetivos pretende alcançar com sua sinergia com o meio ambiente (TINOCO; KRAEMER, 2008).

A justificativa para elaboração deste estudo concentra-se na relevância das informações divulgadas pelas organizações em relação à temática "ambiental" refletindo sobre o comprometimento com a responsabilidade social e a sustentabilidade empresarial (BORGES, 2013).

Considera-se, que as organizações, para se tornarem competitivas no mercado, precisam evidenciar informações relevantes aos usuários que delas se detém para as tomadas de decisões, especialmente sobre a sua atuação diante das atividades desenvolvidas e que estão voltadas ao meio ambiente e a gestão sustentável dos recursos.

Como contribuição para a sociedade esta pesquisa traz um maior conhecimento das informações que estas empresas divulgam da sua relação com o meio ambiente como também as formas como são divulgadas estas informações e para a academia servirá como suporte para futuras pesquisas na área.

O presente estudo além de demostrar o nível das informações ambientais, publicadas pelas empresas do setor Petróleo, Gás e Biocombustíveis listadas e ainda faz um 
comparativo sobre as evidenciações ambientais, bem como destacando aquilo que foi evidenciado.

\section{CONTABILIDADE AMBIENTAL}

A Contabilidade é o campo do saber que se detém ao estudo e exame de registros dos elementos que afetam diretamente o patrimônio de uma entidade (LUZ, 2013). Sua principal finalidade segundo Lima et al. (2012) corresponde ao estudo das variações que acontecem com o patrimônio, de modo quantitativo e qualitativo, com o intuito de fornecer subsídios aos agentes de interesse envolvidos com esse patrimônio.

Nessa perspectiva, a preocupação com as questões ambientais que, nasceu concomitante à expansão da consciência coletiva, fez com que as empresas fizessem uso da Contabilidade Ambiental como aparelho de comunicação com a sociedade.

Carneiro; Luca e Oliveira (2008) explicam que essa necessidade surgiu a partir do dimensionamento dos efeitos da dinâmica empresarial no meio ambiente. Para os autores, essa área da ciência contábil exerce grande importância quando consideramos que pode funcionar como sistema de informação útil à implantação da gestão ambiental dentro de uma empresa.

Tinoco e Kraemer (2008) corroboram com esse pensamento quando colocam que a finalidade da Contabilidade Ambiental é unir a contabilidade financeira aos efeitos ambientais, enfatizando os custos conexos com o meio ambiente. Em suma, faz uma interligação do conceito de sustentabilidade do meio ambiente aos negócios e, para tanto, acolhe todos os subsistemas da empresa.

Autores como Ecker et al. (2014) e Lima et al. (2012) concordam com os autores supramencionados, explicando que o desenvolvimento da Contabilidade Ambiental resultou da consequente necessidade de levar informações adequadas ao funcionamento das empresas. Ou seja, dentro da sociedade contemporânea cresce a busca por informações das questões ambientais na contabilidade das organizações, e além das demonstrações contábeis, procuram-se também outros relatórios capaz 
de subsidiar o gerenciamento ambiental no desenvolvimento de atividades que previnem e recuperam os danos ambientais.

Considerando este aspecto, a Contabilidade Ambiental pode ser considerada como uma subdivisão da Contabilidade que apresenta como objeto de estudo os elementos contábeis referentes ao meio ambiente, e como objetivo, a determinação de eventos e fatos relacionados ao meio ambiente.

Lima et al. (2012, p. 15) chamam de objetivo da Contabilidade Ambiental:

A identificação, a mensuração, o esclarecimento dos eventos e as transações econômico-financeiros que estejam relacionados com a proteção, preservação e recuperação ambiental, ocorridos em um determinado período, visando a evidenciação da situação patrimonial de uma entidade.

A Contabilidade Ambiental, portanto, tem o objetivo de notificar as atividades de uma empresa acerca da a proteção, preservação e recuperação ambiental, ressaltando que os seus efeitos são capazes de influir os negócios da organização.

Para Tinoco e Kraemer (2008), os mais diversos conceitos atribuídos à Contabilidade Ambiental serve para espelhar $r$ evidenciar a relação das organização com o meio ambiente, sendo mais ousada que a contabilidade tradicional, pois se fundamenta em saber as externalidades negativas e registrar, avaliar, mensurar e expor todos os eventos ambientais.

Diante disso, Ecker et al. (2014) afirmam que a contabilidade ambiental se coloca como um desafio novo aos utentes para demonstrar o valor de as organizações atuarem recuperação e preservação do meio ambiente, usando a contabilidade como instrumento que vai auxiliar na tomada de decisões. Pensando nisso, é possível inferi que a contabilidade ambiental se comporta como uma segmentação da contabilidade tradicional e não como uma nova ciência.

A contabilidade ambiental surge não tão somente para atender à finalidade exclusivamente particular e única das empresas (interesse dos sócios e acionistas em não incorrer em prejuízos), mas também à finalidade social de demonstrar em termos monetários o grau de 
destruição potencial em contrapartida às ações de conservação e preservação do bem maior da humanidade: o meio ambiente (ECKER et al., 2014, p. 81).

Destarte, quando os problemas ambientais incomodam os gestores e a sociedade é que a contabilidade ambiental entra em ação, pois, a partir daí, surge a necessidade de informações objetivas e mais precisas sobre o meio ambiente, coisas que os contadores formados pela linha hegemônica não estavam tão habilitados a lidar. Muza; Silveira e Pfitscher (2014, p. 4)

As informações a serem divulgadas pela contabilidade vão desde os investimentos realizados, seja em nível de aquisição de bens permanentes de proteção a danos ecológicos, de despesas de manutenção ou correção de efeitos ambientais do exercício em curso, de obrigações contraídas em prol do meio ambiente, e até de medidas físicas, quantitativas e qualitativas, empreendidas para sua recuperação e preservação.

Nesse sentido, existe uma forte tendência de as empresas exporem para a comunidade, sua política ambiental, o impacto de seu desempenho e os programas de gestão ambiental em seu comportamento econômico e financeiro. Com isso, a Contabilidade Ambiental adquiriu papeis importantes dentro das empresas em geral, pois é através dela que se toma conhecimento da disponibilidade de recursos naturais, e que se constroem debates e discussões no campo econômico, político e social acerca dos impactos da degradação do meio ambiente.

Sendo assim, o debate acerca das questões ecológicas nos negócios das empresas emerge de forma cada vez mais frequente e profunda.

\section{EVIDENCIAÇÃO AMBIENTAL}

Evidenciar pode ser esclarecido como "comprovar, tornar claro, mostrar com evidência (FERREIRA, 2011), consiste em exibir com clareza determinado coisa, não causando dúvidas. Desse modo, a evidenciação contábil se refere às informações que as organizações precisam tornar públicas por meio das demonstrações contábeis (KRESPI et al. 2012). 
A evidenciação contábil é ser explicada como a ação de comunicar aos utentes interessados as informações, utilizando fermentas direcionadas à exposição das informações. Estando relacionadas diretamente, de acordo com Carneiro; De Luca e Oliveira (2008) à assimilação, análise, mensuração e o registro dos fatos que afetam a dinâmica patrimonial.

Em relação a finalidade da evidenciação contábil ambiental, Ribeiro (2010) coloca os seguintes fatos a serem evidenciados: a Natureza dos gastos e os passivos ambientais colocados nas demonstrações contábeis; a imposição para recuperação, assim como as expectativas para a mudança; a interação com o meio ambiente, incluindo as políticas e os programas seguidos ou justificativa para não utilização dos mesmos; os incentivos, as melhorias; etc. Como finalidade da evidenciação contábil, autores como Tinoco e Kraemer (2008, p. 254) definem como "A ação de divulgar as informações do desempenho financeiro, econômico, ambiental e social das entidades aos stakeholders, parceiros sociais, considerando que os demonstrativos e outras maneiras de evidenciação não devem ser enganosos".

Ao se falar das finalidades, Segantini (2012), diz que a divulgação das informações ambientais são proporcionar informações que permitirão aos interessados, analisar o nível de preocupação ambiental das organizações no que tange aos riscos, fluxo de caixa e consistência referente a causa ambiental, podendo ser evidenciadas de formas diversas como exemplo, relatórios da administração, demonstrações contábeis, notas explicativas etc.

Hendriksen e Breda (2010) utilizam o termo em sentido mais amplo ao colocar que evidenciação significa veiculação de informação. Para os autores a informação contábil adquirida dá o respaldo para atuar como instrumento decisório, fazendo preciso alguns atributos de ordem qualitativa tais como: relevância, confiabilidade, tempestividade e compreensibilidade.

Carneiro, De Luca e Oliveira (2008) colaboram relatando que a Contabilidade Ambiental se encontra no Brasil em estágio embrionário, pois, embora muitas empresas venham implantando política de gestão ambiental, existe uma falta na 
divulgação das ações para o público, em virtude da subnotificação dos fenômenos de natureza ambiental nas organizações e deficiência de evidenciação consequente. Isto impetra um gerenciamento melhor das questões ambientais nas organizações, assim como priva o utente de informações que o ajudariam a conhecer com maior propriedade a empresa.

Paiva (2003) declara que os relatórios contábeis que são publicados no país expõem dados incompletos no que tange às atividades relacionadas ao meio, com raras exceções, ambiente. No relatório da administração e em notas explicativas são relatadas, as informações são apresentadas de maneira evasiva, não dando uma clara noção do que acontece realmente. $O$ autor ainda relata que as organizações tendem a divulgar, em suas descontrações voluntárias, apenas os efeitos positivos da relação entre elas e o meio ambiente, descartando, portanto, dados sobre condutas inapropriadas das empresas ligadas aos recursos naturais com temor de que estas informações gerem pressões e agravos à imagem da mesma perante a sociedade.

Falando do ponto de vista da legalidade, são discretas as diretrizes para a divulgação de informações ambientais no campo das demonstrações financeiras. A CVM (1987) no Parecer de Orientação 15 traz diversas recomendações para que as organizações de capital aberto nos relatórios de administração incluam informações aos investimentos efetuados em favor do meio ambiente. O IBRACON - NPA 11 (1996), faz uma recomendação que os passivos/ativos ambientais sejam divulgados nas demonstrações financeiras das organizações, apresentados em títulos específicos, identificando em um segmentação o ativo imobilizado ambiental adequada, os estoques, a participação e a responsabilidade social, definindo que a demonstração referida deve ser exibida junto aos dados do exercício atual e anterior, com o objetivo de realizar um comparativo entre os exercícios ambientais, sociais etc.; assim como os passivos ambientais (financiamentos específicos, contingências ambientais definidas) (KRESPI et al., 2012).

O Conselho Federal de Contabilidade (CFC), por meio da NBC T 15, Resolução no 1.003 de 2004, institui a Demonstração de Informação de Natureza Social e Ambiental, e estabelece procedimentos para a exibição de natureza social e 
ambiental, objetivando revelar à sociedade, a participação e a responsabilidade social da entidade, de modo que contenha informações do exercício atual/anterior, para que se proporcione um comparativo entre os exercícios sociais (KRUGER; SCHUSSLER, ALBERTON, 2011).

A definição do método de divulgação está atrelada à natureza da informação e a sua devida importância. Pensando nisso, ludícibus (2015) cita como métodos mais comuns de divulgação: as demonstrações contábeis, informações entre parênteses, notas explicativas, demonstrações e quadros complementares, comentários no parecer de auditoria, e relatório de administração. Ribeiro (2010) relata que as informações de natureza ambiental precisariam ser divulgadas no corpo das demonstrações contábeis e nas notas explicativas, dependendo da natureza e extensão das informações a serem prestadas.

\section{PROCEDIMENTOS METODOLÓGICOS}

A presente pesquisa classifica-se como um estudo bibliográfico, descritivo, documental e quantiqualitativo. A natureza bibliográfica baseia-se em material já elaborado constituindo-se principalmente de livros, artigos, dissertações e teses. Gil (2009), acrescentando-se o fato de que pesquisa alguma parte atualmente da estaca zero e em algum lugar, pesquisas semelhantes já podem ter sigo feitas ou apenas complementadas (MARCONI; LAKATOS, 2010).

Já a pesquisa descritiva, segundo Andrade (2003, p. 124) ele defende a ideia de que "uma das características da pesquisa descritiva é a técnica padronizada da coleta de dados, realizada principalmente através de questionários e da observação sistemática". Na mesma obra, o referido autor afirma que neste tipo de pesquisa, "os fatos são observados, registrados, analisados, classificados e interpretados, sem que o pesquisador interfira neles".

A análise documental segundo Marconi e Lakatos (2010) constitui uma técnica importante na pesquisa, seja complementando informações obtidas por outras técnicas, seja desvelando aspectos novos de um tema ou problema. 
O método quantitativo como o próprio nome indica, caracteriza-se pelo emprego da quantificação, tanto nas modalidades de coleta de informações, como também no tratamento das mesmas através de técnicas estatísticas, que vão desde as mais simples (percentual, média, desvio-padrão) às mais complexas (coeficiente de correlação, análise de regressão etc.). (RICHARDSON, et al. 2011, p. 60). Enquanto o método qualitativo caracteriza-se por sua vez, pela a complexidade de determinado problema, sendo necessário compreender e classificar os processos dinâmicos vividos nos grupos, contribuir no processo de mudança, possibilitando o entendimento mais claro do assunto (MARCONI; LAKATOS, 2010).

A metodologia utilizada neste trabalho foi baseada em Marion e Costa (2007), onde eles verificaram a uniformidade das informações ambientais entre os relatórios disponibilizados pelas empresas do setor de papel e celulose através do site da BOVESPA e de seus sites oficiais.

O Universo da pesquisa é composto pelas empresas listadas na Bovespa, mas para o desenvolvimento desta pesquisa foi selecionada apenas uma amostra, composta pelas empresas listadas no setor de Petróleo, Gás e Biocombustíveis no período de 2015 a 2017. O quadro 1 mostra as empresas abaixo mostra as empresas estudadas.

Quadro 1: Relação das empresas componentes da amostra.

\section{Empresas}

\section{COSAN LIMITED}

COSAN S.A Industria e comercio

OGX PETROLEO E GAS S. A

PETRO RIO S. A

PETROLEO BRASILEIRO S.A PETROBRAS

QGEP PARTICIPAÇÕES S. A

REFINARIA DE PETROLEOS MANGUINHOS S. A

ULTRAPAR PARTICIPAÇÕES S. A

Fonte: BMFBOVESPA, 2019. 
A coleta de dados foi realizada através dos sites da BOVESPA e sites oficiais das empresas selecionadas, no período de 2015 a 2017, com objetivo de verificar se existe uniformidade na evidenciação das informações ambientais, publicadas pelas empresas do setor Petróleo, Gás e Biocombustíveis listadas na Bovespa.

Os documentos analisados foram os Relatórios da Administração, Notas Explicativas, Relatório de Sustentabilidade, Balanço Social etc. Para subsidiar a análise descritiva dos dados utilizou-se do software Microsoft Excel 2010.

\section{APRESENTAÇÃO E ANÁLISE DOS RESULTADOS}

Nesta seção, são apresentados os resultados da pesquisa, o qual teve por objetivo verificar se existe uniformidade na evidenciação das informações ambientais, publicadas pelas empresas do setor Petróleo, Gás e Biocombustíveis no período de 2015 a 2017. A escolha da amostra é justificada por ser um dos setores que maior apresenta potencial de poluição. Portanto, trata-se de um universo bom para examinar se a responsabilidade ambiental destas organizações, refletida nas suas políticas de gestão ambiental, é evidenciada adequadamente para a sociedade nas demonstrações financeiras.

$\mathrm{Na}$ Tabela 1 estão contidas as empresas listadas na BOVESPA classificadas no setor petroquímico (Exploração, Refino e Distribuição) bem como, a Demonstração do Resultado - Consolidado com o Lucro (Prejuízo) do Período (2015 a 2017) R\$ - mil.

Tabela 1: Relação das empresas e seu Lucro/Prejuízo no ano de 2015 a 2017.

\begin{tabular}{|l|l|l|l|}
\hline Empresas & $\begin{array}{l}\text { Lucro (Prejuízo) do } \\
\text { Período }\end{array}$ & $\begin{array}{l}\text { Lucro } \\
\text { (Prejuízo) do } \\
\text { Período }\end{array}$ & $\begin{array}{l}\text { Lucro } \\
\text { (Prejuízo) do } \\
\text { Período }\end{array}$ \\
\hline COSAN LIMITED & 799.761 & $\begin{array}{l}(2016) \mathrm{R} \$ \\
\text { mil } \$\end{array}$ & $\begin{array}{l}(2017) \mathrm{mil} \$ \\
\text { mil }\end{array}$ \\
\hline
\end{tabular}




\begin{tabular}{|l|l|l|l|}
\hline $\begin{array}{l}\text { COSAN S.A Industria e } \\
\text { comercio }\end{array}$ & 881.762 & 1.390 .087 & 1.510 .530 \\
\hline $\begin{array}{l}\text { OGX PETROLEO E GAS S. } \\
\text { A }\end{array}$ & $(106.799)$ & $(179.059)$ & 357.172 \\
\hline $\begin{array}{l}\text { PETRO RIO S. A } \\
\text { PETROLEO BRASILEIRO } \\
\begin{array}{l}\text { S.A PETROBRAS } \\
\text { QGEP PARTICIPAÇÕES S. }\end{array}\end{array}$ & $(35.171 .000)$ & $(13.045 .000)$ & 377.000 \\
\hline $\begin{array}{l}\text { A DE } \\
\text { REFINARIA } \\
\text { PETROLEOS } \\
\text { MANGUINHOS S. A }\end{array}$ & $(482.566)$ & 97.673 & 314.587 \\
\hline $\begin{array}{l}\text { ULTRAPAR } \\
\text { PARTICIPAÇÕES S. A }\end{array}$ & 1.512 .972 & $(565.113)$ & $(236.025)$ \\
\hline
\end{tabular}

Fonte: BMFBOVESPA, 2019.

Dentre as empresas destacadas no quadro 1 a OGX PETROLEO e GAS S.A não foi analisada pois a mesma se encontra em recuperação judicial, ou seja, é uma medida para conter a falência de uma organização. É pedida quando a organização perde a sua capacidade de pagar as suas dívidas.

No quadro 2 abaixo, é destacado as categorias analisadas a partir do referencial, adaptado do estudo de Carneiro; De Luca e Oliveira (2008, p. 39).

Quadro 2: Categorias Analisadas.

\begin{tabular}{|l|l|}
\hline Categorias & Descrição \\
\hline Demonstrações & $\begin{array}{l}\text { Provisão para despesas com danos/remediação } \\
\text { ambientais; seguro contra acidentes/desastres } \\
\text { Financeiras Ambientais } \\
\text { ambientais }\end{array}$ \\
\hline
\end{tabular}


Notas Explicativas

Relatório

Administração

Relatório

sustentabilidade

Balanço Social

Demonstrações

de

Informações de Natureza

Social e Ambiental (NBC T 15)
Os ativos ambientais, apresentando-se a participação em cada grupo de forma sintetizada e a natureza e finalidade desses ativos, no caso de ovas aquisições;

da Tem por função apresentar as demonstrações contábeis sob a ótica da administração da empresa, ou seja, é capaz de facilitar o entendimento das informações descritas nas demonstrações contábeis.

de Consiste em uma das formas mais comuns de uma empresa descrever e prestar contas de sua atuação e conduta para a sustentabilidade, à sociedade e ao mercado.

Relata o nível de responsabilidade social que uma empresa assumiu, portanto, é uma forma da empresa prestar contas pelo uso do patrimônio público.

Procedimentos de natureza social e ambiental, com o objetivo de demonstrar à sociedade a participação e a responsabilidade social das entidades

Fonte: Adaptado de Carneiro; De Luca e Oliveira (2008, p. 39).

Foram definidas características também para o tipo de evidenciação: T1 - declarativa: as informações expressas de maneira descritiva, sem qualquer quantificação financeira; e T2 - quantitativa monetária: as informações quantitativas apresentadas e expressas em números de natureza financeira (CARNEIRO; DE LUCA; OLIVEIRA, 2008).

Importante salientar que informações repetidas em um mesmo relatório foram consideradas uma única vez somente, assumindo que repetições em partes distintas de um relatório do mesmo período, não significam abrangência necessariamente ou completude de evidenciação.

Tabela 2: Demonstrações das empresas no período de 2015 a 2017. 
Demonstrações Padronizadas

\begin{tabular}{|c|c|c|c|c|c|c|c|c|c|c|c|c|}
\hline \multirow{2}{*}{$\begin{array}{l}\text { Categorias } \\
\text { Empresas }\end{array}$} & \multicolumn{2}{|c|}{$\begin{array}{l}\text { Demonstr. } \\
\text { Financeiras }\end{array}$} & \multicolumn{2}{|c|}{$\begin{array}{l}\text { Notas } \\
\text { Explicativas }\end{array}$} & \multicolumn{2}{|c|}{$\begin{array}{l}\text { Relatório } \\
\text { da Adm. }\end{array}$} & \multicolumn{2}{|c|}{$\begin{array}{l}\text { R. de } \\
\text { Sustenta. }\end{array}$} & \multicolumn{2}{|c|}{$\begin{array}{l}\text { Balanço } \\
\text { Social }\end{array}$} & \multicolumn{2}{|c|}{$\begin{array}{l}\text { NBC-T } \\
15\end{array}$} \\
\hline & T1 & T2 & T1 & T2 & T1 & T2 & T1 & T2 & T1 & T2 & T1 & T2 \\
\hline COSAN & 3 & 0 & 2 & 0 & 3 & 0 & 3 & 0 & 0 & 0 & 0 & 0 \\
\hline COSAN S. A & 2 & 0 & 4 & 0 & 3 & 1 & 3 & 0 & 0 & 0 & 0 & 0 \\
\hline $\begin{array}{l}\text { PETRO RIO S. } \\
\text { A }\end{array}$ & 2 & 0 & 2 & 0 & 3 & 0 & 0 & 0 & 0 & 0 & 0 & 0 \\
\hline PETROBRAS & 4 & 5 & 3 & 5 & 3 & 3 & 3 & 4 & 3 & 4 & 0 & 0 \\
\hline QGEP & 3 & 2 & 2 & 0 & 3 & 3 & 1 & 2 & 0 & 3 & 0 & 0 \\
\hline MANGUINHOS & 5 & 2 & 3 & 0 & 1 & 0 & 1 & 0 & 0 & 0 & 0 & 0 \\
\hline $\begin{array}{l}\text { ULTRAPAR S. } \\
\text { A }\end{array}$ & 4 & 3 & 3 & 6 & 1 & 1 & 1 & 2 & 0 & 0 & 0 & 0 \\
\hline
\end{tabular}

Fonte: BMFBOVESPA, 2019.

Para melhor entendimento cada empresa foi analisada separadamente, foram também destacados os conteúdos das demonstrações ambientais.

\subsection{GRUPO COSAN}

Nas empresas Cosan llimited e Consan S.A que atuam na produção de açúcar, etanol, cogeração de energia, dentre as suas demonstrações no período de 2015 a 2017 houve destaque apenas para 3 relatório de sustentabilidade realizado pela Raízen, que representa uma evolução para uma investida mais direcionada aos temas relevantes, inserida a partir de consulta aos seus stakeholders e de uma nova definição da materialidade, fundamentos básicos do processo. Em 2015 foi o quarto relatório da Raízen seguindo a versão das diretrizes da Global Reporting Initiative (GRI), utilizadas a partir da segunda edição do documento.

Outras demonstrações da Cosan llimeted são demonstrações financeiras trimestrais, entretanto não há descrito nenhum gasto da organização em relação as suas políticas ambientais. Desse modo, o grupo Cosan evidencia muito pouco as suas informações 
ambientais, tanto em relação as informações inseridas no Relatório de Sustentabilidade, quanto em relação ao seu site da internet.

Segundo os relatórios da Cosan a companhia especifica a sustentabilidade enquanto um direcionador estratégico, gerando crescimento e valor com transparência, responsabilidade socioambiental e boas práticas de risco, gestão e governança corporativa. Entretanto analisando os documentos da empresa é possível perceber que essa política de sustentabilidade começou apenas em 2012, quando o Grupo Cosan deu início à consolidação e elaboração de seu modelo de gestão sustentável, o qual foi fundamentado em quatro processos diretrizes e estratégias, verificação e relato, diagnóstico e avaliação e implementação e acompanhamento. No entanto sua evidenciação ambiental ao longo do período analisado mostrou-se insuficiente.

\subsection{PETRORIO}

A PetroRio S.A atua na produção de óleo/gás natural do Brasil, a organização opera o Campo de Polvo desde o começo de 2014, produzindo mais de 8 mil barris/dia, sendo a $6^{a}$ maior produtora de barris do país. Com esta produção, a referida organização já desponta entre as 10 maiores do Brasil.

Sobre a evidenciação de informações ambientais no período de 2015 a 2017, a empresa apresentou poucos resultados, lançando apenas dois relatórios da administração abordando meio ambiente, segurança, responsabilidade socioambiental. Nestes relatórios a empresa relata o compromisso com a segurança dos colaboradores, parceiros e o respeito ao meio ambiente, onde norteia todos os negócios da organização. A Petro Rio mostrou em seus relatórios as informações diversificadas ligadas a questão ambiental. A evidenciação de investimentos com projetos ambientais apresentou os dados sem detalhamento, colocando os valores junto a projetos sociais. As notas explicativas não trazem qualquer informação utilizável no estudo e em seu website não contém nenhum relatório de sustentabilidade. 
No site da PetroRio são destacados alguns projetos ambientais e de segurança operacional a organização relata atender aos requisitos legais brasileiros e de agências ambientais.

\subsection{PETROBRÁS}

A Petrobrás umas das maiores empresa do Brasil de capital aberto, cujo acionista majoritário é o Governo do Brasil, sendo, uma empresa portanto, estatal de economia mista. Com sua sede no Rio de Janeiro, opera em 25 países atualmente, no segmento de energia, nas áreas de refino, exploração, produção, comercialização e transporte de petróleo e seus derivados.

Segundo o site da Petrobrás na área de meio ambiente a empresa busca cuidar da segurança das operações e ampliar as ações para o equilíbrio entre atividades e o bem-estar das comunidades. Para tanto, a organização busca o aperfeiçoamento dos seus produtos e dos processos, treinamentos, o aumento da eficiência e patrocínios projetos de preservação e conservação de ecossistemas, buscando contribuir com o desenvolvimento sustentável.

No período de 2015 a 2017 empresa emitiu diversas demonstrações financeiras, notas explicativas, relatórios da administração e três relatórios de sustentabilidade. Em um desses relatórios da administração a empresa divulgou que em 2015, aplicou $R \$ 6,9$ bilhões em projetos e operações relacionados à gestão integrada de saúde e meio ambiente. Nesse contexto, as iniciativas foram para aperfeiçoar o desempenho nessas áreas, atender à legislação e contribuir diretamente para que as práticas operacionais das unidades para que sejam rentáveis, seguras e responsáveis ambientalmente.

Entre essas iniciativas da empresa, está a certificação com as normas ISO 14001 (gestão ambiental) e OHSAS 18001 (gestão de saúde e segurança) dos sistemas de gestão de saúde e meio ambiente das suas unidades no Brasil e exterior. No período analisado, todo o petróleo refinado pela empresa foi processado em unidades que eram certificadas. 
Em uma nota explicativa a empresa divulgou dados de vazamento de petróleo e

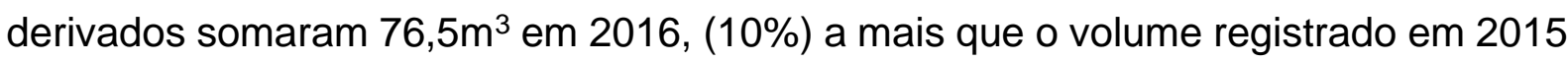
e (84\%) inferior ao Limite de fixado em $461 \mathrm{~m}^{3}$. Os níveis de derramamento permaneceram inferiores a $1 \mathrm{~m}^{3}$ por milhão de barris produzido, se constituindo um excelente resultado na indústria mundial.

A empresa relata que manteve os procedimentos e os planos de respostas a vazamentos em níveis local, corporativo e regional. Para atuar de forma eficiente nessas situações, a Petrobrás dispõe dos seguintes recursos: 36 embarcações para o recolhimento do óleo; 113 embarcações para apoio; 270 recolhedores; 140 mil litros de dispersantes químicos, cerca de 95 mil metros de barreiras de contenção; além de outros itens de segurança. Esses recursos estão distribuídos nos Centros de Defesa Ambiental, Centros de Resposta a Emergência e nas bases avançadas em vários pontos do território nacional. No período de 2015 a 2017, a empresa realizou 65 exercícios simulados, incluindo treinamentos de resposta a vazamentos.

Nos relatórios de sustentabilidade compilou todas as informações sobre desempenho, estratégia e gestão quanto a aspectos de sustentabilidade. Foram analisados 26 temas a partir de questões relacionadas às práticas de estratégia e governança, a exigências legais e regulatórias, a expectativas de alguns dos seus públicos de interesse, a referências internacionais no setor de óleo e gás e a identificação de macrotendências. O resultado dessa análise permitiu priorizar para o relato da sustentabilidade.

Nos balanços sociais no período analisado a Petrobrás Investiu cerca de $R \$ 950,2$ milhões em mais de 1000 projetos sociais, de esporte educacional e ambientais. Por meio do Programa Petrobras Socioambiental, articulou-se iniciativas que contribuem para criação soluções e oferecimento de alternativas com potencial para o enfrentamento de questões sociais e ambientais relevantes para o país.

A Petrobrás apresenta um grande número de informações ambientais, onde as mesmas são de fácil acesso e bem explicadas. A empresa evidencia os gastos com manutenção nos processos operacionais para a melhoria do meio ambiente e 
investimentos com projetos ambientais de forma satisfatória, apresentando também detalhadamente a quantidade dos processos ambientais e o valor das indenizações relativas à matéria ambiental.

\subsection{QGEP PARTICIPAÇÕES S.A}

A Queiroz Galvão Exploração e Produção (QGEP), é uma organização do Grupo Queiroz Galvão, atuado na exploração e na produção de óleo e gás, detendo cerca de 14 concessões em oito das bacias offshore da costa brasileira.

$\mathrm{Na}$ evidenciação contábil da empresa, no período houve destaque para alguns relatórios da administração, três Relatório de Sustentabilidade e algumas ações descritas no site da QGEP. Nos relatórios da administração não menciona valores, é apenas notas qualitativas, relatando que a empresa prioriza a avaliação dos impactos e o gerenciamento dos potenciais riscos sociais, ambientais e de segurança associados às suas atividades, agindo para o seu controle. Além de procurar o comprometimento dos envolvidos com suas atividades (contratados e colaboradores), para que tenha um bom desempenho operacional, ambiental e de responsabilidade social.

Em 2015, destaca-se a recertificação nas normas ISSO 14001 (Sistema de Gestão Ambiental) e OHSAS18001 (Sistema de Gestão de Saúde e Segurança) para gestão das atividades de produção e exploração, que corroboram com o compromisso de melhorar constantemente os processos.

Nos relatórios de sustentabilidade foi realizado o tratamento das informações para a elaboração do Relatório Anual de Sustentabilidade. Em 2015, a QGEP não atuou como operadora e, por isso, seu consumo em relação à energia e água foi relativo às suas atividades administrativas, e, portanto, bem menor do que o gerado em 2014. Ao longo do período, os esforços da Companhia envolveram o aprimoramento dos procedimentos, treinamentos continuados em resposta a emergências e maior sinergia com outras operadoras, em busca de melhoria de performance. 
Elaboração dos estudos ambientais em 2015 foi um ano de entregas de estudos para obtenção de licenças ambientais e autorizações da ANP. No ano, foi obtida a Licença Prévia referente ao SPA e foram submetidos ao Ibama os dois estudos ambientais referentes às atividades de perfuração nos blocos das bacias de Foz do Amazonas e Pará-Maranhão, operadas pela QGEP. A Companhia também acompanhou por meio de TCMs e OCMs os processos de licenciamento em áreas onde não atua como operadora.

Nos Investimentos e gastos com proteção ambiental no período analisado a empresa investiu 68.745,85 em tratamento e disposição de resíduos e 575.166,74 com custos de prevenção e gestão ambiental, totalizando 613.912,59.

No site da Queiroz Galvão Exploração e Produção relata que a empresa participa do projeto conjunto de proteção e limpeza de costa (PPLC), promovido no âmbito do acordo de cooperação técnica entre o IBP e o IBAMA. Este projeto teve como objetivo visa a criar um banco de dados georreferenciado de toda a costa brasileira, que é os dados obtidos incluem informações tais como características físicas e socioambientais da costa brasileira, acessibilidade, entre outras, promovido no âmbito do acordo de cooperação técnica entre o IBP e o IBAMA.

A QGEP atualmente conhecida como Enauta, se tornou a primeira operadora brasileira independente na área premium do pré-sal, no Campo de Atlanta e, alargaram caminhos para produção de mais de (20\%) de gás no Nordeste, visto que a organização acredita ter achado o Campo de Manati. A organização cresce respeitando as pessoas o e o meio ambiente, investindo no potencial e segurança das mesmas (QGEP, 2019).

A QGEP Participações evidenciou os gastos e os investimentos com outros projetos ambientais, bem como os valores das multas e das indenizações relativas à área ambiental. O ano de 2015 teve pouca evidenciação, pois os investimentos com preservação de ambientes passaram a ser apresentados a partir do ano de 2016, bem como os passivos e as contingências ambientais, entretanto ainda de forma deficitária. 


\subsection{REFINARIA DE PETRÓLEOS MANGUINHOS S.A}

A Refinaria de Petróleos Manguinhos é uma Sociedade de capital aberto, que tem por finalidades sociais: (1) a exploração, no Estado do Rio de Janeiro, de uma refinaria de petróleos e de indústrias independentes ou conexas, desde que não se contraponha a ato do Governo Federal; (2) a importação de petróleos crus, a venda de derivados de petróleos e a sua exportação quando autorizada; e (3) a prestação de serviços a atividade de refino.

Na questão da evidenciação a empresa no período de 2015 a 2017 divulgou poucas informações ambientais, houve destaque apenas para uma nota explicativa a sobre a certificação pela Bureau Veritas Certification-Brasil de seu Sistema de Gestão Ambiental que foi recomendado para certificação segundo os requisitos da NBR ISSO 14001.

No site da Refinaria de Petróleos Manguinhos relata que a empresa possui um gerenciamento de resíduos, onde os resíduos são transportados e destinados adequadamente, segundo legislação aplicável. Além de que os lançamentos de efluentes são encaminhados ao sistema de tratamento através de rede coletora, atendendo aos padrões de lançamento da legislação vigente.

A Refinaria Manguinhos não apresentou nesse período nenhum relatório de balanço social ou sustentabilidade. As análises das suas informações foram retiradas somente de notas explicativas no qual não existe qualquer tipo de evidenciação, não foram encontradas também informações nos administrativos, relatórios anuais e release de resultados. Portanto, a empresa foi classificada como insuficiente em relação ao nível de evidenciação.

\subsection{ULTRAPAR PARTICIPAÇÕES S.A}

A Ultrapar Participações S.A é uma sociedade de capital aberto com sede em São Paulo - SP. A Sociedade tem por finalidade a aplicação de capitais próprios no 
comércio, na indústria e na prestação de serviços, mediante a subscrição ou aquisição de ações e cotas de outras sociedades. Através de suas controladas,

atua no segmento de distribuição de gás liquefeito de petróleo - GLP (Ultragaz), na distribuição de combustíveis e atividades relacionadas (Ipiranga), na produção e comercialização de produtos químicos (Oxiteno), na prestação de serviços de armazenagem de granéis líquidos (Ultracargo) e no comércio de medicamentos, produtos de higiene, beleza e cosméticos, através da Imifarma Produtos Farmacêuticos e Cosméticos (Extrafarma) (ULTRAPAR, 2018 p.15).

Sobre a evidenciação da companhia no período de 2015 a 2017 a empresa lançou diversas notas explicativas e relatórios da administração relando que a Ultrapar busca manter a valorização da ética, da cidadania, da cultura e da excelência nos padrões de meio ambiente, saúde e segurança cultivando uma história de quase 80 anos com seus stakeholders. O Modelo de Sustentabilidade da empresa abrange cinco pilares: Pessoas, Segurança, Cadeia de Valor, Produtos/Serviços e Meio Ambiente, e, que se distendem em 28 indicadores de gestão e desempenho, e estão alinhados às diretrizes de sustentabilidade corporativas.

Em função das particularidades de cada mercado que a mesma opera, a empresa mantém políticas relacionadas à atuação socioambiental, de segurança e saúde que têm como base essas diretrizes.

Em umas das notas explicativas a empresa possuem provisões para litígios sobre cláusulas de indenizações para questões regulatórias e ambientais, no valor de $R \$$ 60.293 em 2015.

A Sociedade e suas controladas possuem passivos contingentes de natureza cível, ambiental e regulatória no valor de $\mathrm{R} \$ 582.960$ em 2015, dos quais se destacam: A controlada Cia. A Ultragaz respondeu a processo administrativo junto ao Conselho Administrativo de Defesa Econômica (CADE), sob alegação de prática anticoncorrencial em municípios da região do Triângulo Mineiro no ano de 2001 , no qual foi condenada à uma multa de $R \$ 23.104$. Essa decisão teve sua execução suspensa por ordem judicial e o mérito está em debate na esfera judicial. 
Outra nota relata o incêndio ocorrido em 2 de abril de 2015 no terminal de Santos da controlada Tequimar, a CETESB - Companhia Ambiental do Estado de São Paulo imputou multa de $\mathrm{R} \$ 22.500$, em razão dos alegados impactos ambientais e urbanos ocasionados pelo incidente. Diante da autuação, foi apresentada a respectiva impugnação ainda na esfera de primeira instância, junto ao órgão ambiental, na qual foi arguida, entre outros aspectos, a inaplicabilidade de legislação federal, visto a existência de legislação estadual que regula a matéria, o que pode ensejar na redução da multa aplicada.

Nos relatórios de sustentabilidade da empresa destaca a convicção de que o tratamento adequado ao meio ambiente é um dos principais pilares do desenvolvimento sustentável de uma companhia.

A preservação do meio ambiente permeia programas e projetos voltados a redução e o controle da emissão de poluentes e rejeitos, o uso de forma racional e sem desperdício das matérias-primas e a abordagem da reciclagem, bem como conscientiza sobre a importância do meio ambiente a cada público associado a empresa.

Nesse sentido, a Ultrapar Participações é uma empresa com um bom nível de evidenciação, pois apresentou no período analisado a informação referentes aos valores indenizações e das multas ambientais, gastos com a manutenção nos processos operacionais de melhora do meio ambiente, passivos e contingências, gastos com os outros projetos ambientais, todos descritos de maneira satisfatória.

\section{CONSIDERAÇÕES FINAIS}

Atualmente, a divulgação das informações ambientais é de grande importância para o desenvolvimento de uma correta gestão ambiental nas empresas, além de servir de suporte para as tomadas de decisões financeiras e de produção, representando também um forte instrumento de reconhecimento social, pelo fato de registrar os eventos relacionados às atividades empresariais que impactam, de uma forma ou outra, o ambiente em que estas empresas se encontram inseridas. 
Diante dos aspectos analisados, constatou-se que as empresas com o maior número de informações ambientais divulgadas em seus instrumentos de evidenciação foram a Petrobras e Ultrapar apresentando um número maior de informações ambientais que as outras empresas pesquisadas.

O maior número de informações ambientais evidenciadas por essas duas empresas, referem-se ao relatório de sustentabilidade, notas explicativas e relatórios da administração. Há de ressaltar a preferência pelos relatórios de sustentabilidade para divulgação das informações ambientais, o que se pode atribuir à questão da dificuldade de mensuração quantitativa dos eventos ambientais, bem como, da falta de exigibilidade por parte da legislação vigente de evidenciação dessas informações em seus relatórios mais tradicionais e convencionais.

Nas outras empresas pode constatar que prevalece a divulgação de informações ambientais através do Relatório da Administração e algumas notas explicativas. Isto apresenta uma dissociação entre as informações divulgadas e as declarações financeiras, causando, consequentemente, uma perda na eficiência da informação, no qual revela que o potência máximo da Contabilidade Ambiental ainda não foi exercido.

Assim, nas empresas Cosan, Queiroz Galvão Exploração e Produção, Refinaria Manguinhos e PretoRio não há muita diferença entre a quantidade de informações divulgadas, todas apresentam uma rasa explicação referente a informação evidenciada em seus relatórios anuais. Há também que se analisar que dessas empresas apenas o grupo Cosan não está com dificuldade financeira.

Os resultados mostraram que que há uma prevalência de construções puramente declarativas, informações qualitativas, desvinculadas de mensuração, quer em termos físicos quer em termos monetários. Demonstra uma incompletude no processo de evidenciação, pois dificulta ao usuário estabelecer significações econômicas das informações divulgadas, fazer relações entre itens de mesma natureza, efetuar comparações. Em sua maioria, as informações divulgadas perdem em relevância, 
utilidade, valor preditivo, comparabilidade e verificabilidade, pois se apresentam nos demonstrativos de maneira inadequada e incompleta.

Pode-se inferir que as duas empresas Petrobrás e Ultrapar tratam as interrogações ambientais com comprometimento e seriedade, buscando inserir práticas e ações que resultem na recuperação e conservação do meio ambiente e na diminuição do impacto resultante de suas atividades.

Por fim, considera-se que, o estudo concretizou o objetivo proposto inicialmente e respondeu à questão da pesquisa de maneira satisfatória. Porém as empresas deveriam divulgar mais informações ambientais e com maiores detalhes em seus demonstrativos obrigatórios anuais, como forma de identificar de forma clara e transparente o relacionamento dessas empresas com o meio ambiente, facilitando a tomada de decisão dos stakeholders, bem como, consolidando a imagem e reputação, dessas empresas como organização ambientalmente responsável.

\section{REFERÊNCIAS}

ANDRADE, M. M. de. Introdução à metodologia do trabalho científico: elaboração de trabalhos na graduação. 5. ed. São Paulo: Atlas, 2003.

BORGES, A. L. Sistema de ensino presencial conectado curso superior em ciências contábeis. Trabalho de Conclusão de Curso apresentado ao Curso de Ciências Contábeis da UNOPAR, Universidade Norte do Paraná, 2013.

BOVESPA. Site Institucional BM\&FBOVESPA E CETIP. Disponível em: http://www.bmfbovespa.com.br/pt_br/index.htm. Acesso em: 27 março de 2019.

CARNEIRO, J. E.; DE LUCA M. M. M.; OLIVEIRA, M. C. Análise das Informações Ambientais Evidenciadas nas Demonstrações Financeiras das Empresas Petroquímicas Brasileiras listadas na Bovespa. Revista Contabilidade Vista e Revista, Belo Horizonte, v. 19, n. 3, p. 39-67, 2008. 
COMISSÃO DE VALORES MOBILIÁRIOS. Parecer de Orientação no 15, de 1987. Procedimentos observados pelas companhias abertas e auditores na elaboração e publicação das demonstrações financeiras, do relatório da administração e do parecer de auditoria relativos aos exercícios sociais encerrados a partir de dezembro de 1987.

CONSELHO FEDERAL DE CONTABILIDADE. Resolução CFC n. 1.003, de 19 de agosto de 2004. Aprova a NBC T 15 - Informações de Natureza Social e Ambiental: CFC, 2004.

COSAN LIMITED. Site Cosan. Disponível em http://cosan.com.br/pt-br. Acesso em março de 2019.

COSTA, R. S. da; MARION, J. C. A Uniformidade na evidenciação das informações ambientais. Revista Contabilidade \& Finanças. USP: São Paulo, v. 12, n. 43, p. 2033, 2007.

ECKERT, A.; et al. Evidenciação Contábil das Informações Ambientais: Uma Análise das Empresas da Serra Gaúcha Listadas na Bovespa. Revista Rosa dos Ventos Turismo e Hospitalidade, v. 6, n. 4, pp. 508-530, 2014.

FERREIRA, A. C. de S. Contabilidade ambiental. 3 ed. São Paulo: Atlas, 2011.

GIL, A. C. Como elaborar projetos de pesquisa. 5. ed. São Paulo: Atlas, 2009.

HENDRIKSEN; E. S.; BREDA, M. F. V. Teoria da contabilidade. 4 ed. São Paulo: Atlas, 2010.

INSTITUTO BRASILEIRO DOS AUDITORES INDEPENDENTES - IBRACON. Normas e procedimentos de auditoria - NPA 11 - Balanço e Ecologia. 1996.

IUDÍCIBUS, S. de. Teoria da contabilidade. 11. ed. São Paulo: Atlas, 2015.

KRESPI, N. T.; et al. Evidenciação de informações ambientais: Análise sob o aspecto do balanço social de empresas listadas na ISE. Custos e Agronegócio online, v. 8, n. 4, p. 147-170, 2012. 
KRUGER, D. S.; SCHUSSLER, A. M.; ALBERTON, L. Evidenciação de Informações Sociais e Ambientais. XIV SemeAD: Seminários em Administração, 2011.

LIMA, K. P. S. de. et al. Contabilidade Ambiental: Um estudo sobre a evidenciação das informações ambientais nas demonstrações contábeis das grandes empresas brasileiras. Revista Eletrônica de Administração (Online), v. 11, n.1, edição 20, 2012.

LUZ, L. V. N. Análise sobre a evidenciação de melhores práticas socioambientais pelos 20 maiores bancos que atuam no SFN. Trabalho de conclusão de Curso (TCC) apresentado como um dos requisitos para a obtenção do título de bacharel em Ciências Contábeis do UniCEUB - Centro Universitário de Brasília, 2013.

MARCONI, M. A; LAKATOS, E. M. Técnicas de Pesquisa. 6 ed. São Paulo: Atlas, 2010.

MUZA, T. N.; SILVEIRA, M. L. G. da.; PFITSCHER, E. D. Aplicação do Sistema Contábil Gerencial Ambiental (SICOGEA) em uma Instituição Federal de Ensino e Tecnologia. Congresso UFSC de Controladoria e Finanças \& Iniciação Científica em Contabilidade, 2014.

PAIVA, P. R. de. Contabilidade Ambiental: Evidenciação dos gastos ambientais com transparência e focada na prevenção. São Paulo: Atlas, 2003.

PETRO RIO S.A. Site Institucional Petro Rio. Disponível em: http://www.petroriosa.com.br/default_pt.asp?idioma=0\&conta=28. Acesso em março de 2017.

PETROLEO BRASILEIRO S.A PETROBRAS. Site Institucional da Petrobrás. Disponível em: http://www.petrobras.com.br/pt/. Acesso em março de 2019.

QGEP PARTICIPAÇÕES S.A. Site Queiroz Galvão. Disponível em: http://www.qgep.com.br/. Acesso em março de 2019. 
REFINARIA DE PETROLEOS MANGUINHOS S.A. Site Institucional da Empresa. Disponível em: http://www.refinariademanguinhos.com/. Acesso em março de 2019.

RIBEIRO, M. de S. Contabilidade ambiental. 2 ed. São Paulo: Saraiva, 2010.

RICHARDSON, R. J.; et al. Pesquisa social: Métodos e Técnicas. 3ª Edição. São Paulo. Atlas, 2011.

SEGANTINI, G. T. Análise da relação entre condutas ambientais das empresas listadas no Índice de Sustentabilidade Empresarial e o seu desempenho econômico. Dissertação de Mestrado em Ciências Contábeis: Universidade Federal do Rio Grande do Norte. Natal, RN, 2012.

TINOCO, J. E. P.; KRAEMER, M. E. P. Contabilidade e gestão ambiental. 2 ed. São Paulo: Atlas, 2008.

ULTRAPAR PARTICIPAÇÕES S.A. Site Institucional da Empresa. Disponível em: http://www.ultra.com.br/. Acesso em março de 2019.

Enviado: Outubro, 2020.

Aprovado: Novembro, 2020. 